\title{
The United Church of Canada's Reconciliation Documents and the Indexing of Collective Memory
}

\begin{abstract}
:
Following a distinct trajectory in the field of Knowledge Organization, I explore how indexes are part of the structure of our everyday lives. Drawing on extensive archival research, I look at documents created and used by the United Church of Canada as part of its reconciliation work with Indigenous peoples. I conclude that these documents index the narrative the church tells about itself-and therefore its identity - as part of the development and maintenance of the UCC's evolving collective memory. My findings reinforce Knowledge Organization's new line of inquiry while also complicating its message concerning the nature of infrastructure.
\end{abstract}

\section{Introduction / Background}

A distinct approach in the field of Knowledge Organization (KO) views indexes as part of the process and structure of our daily lives, not just found in catalogues, databases, or the backs of books. Adopting this position, I examine documents created and used by the United Church of Canada (UCC) in its reconciliation work with Indigenous peoples and find that these documents index the UCC's collective memory, and in turn, help to structure the church's identity. Collective memory often is founded on pivotal events or ideas, and for the UCC as a reconciling community, that point of origin is the church's 1986 Apology to Indigenous Peoples. In the 34 years since that event, the UCC's collective memory has shifted. Settler-colonialism — "a system [like colonialism] defined by unequal relationships ... where an exogenous collective [unlike colonialism] aims to locally and permanently replace indigenous ones" (Veracini 2017, 4) —was always an unspoken part of the church's history, but since the Apology, settler-colonialism is part of the story the church tells about itself. The Apology was documented, copied and distributed, and now is referenced in many of the other documents used by the church to encourage reconciliation. These documents echo the Apology, repeatedly pointing to the event to reinforce it while allowing for a nuanced narrative to form around it.

\section{Theoretical Framework and Questions}

Traditionally in Library and Information Science, an index is something that "leads from a known order of symbols to an unknown order of information" (Weinberg 2017, 1978). My study expands beyond indexing's traditional environment within the library profession's structures and practices, where the index is limited to the matching of information to information seekers. Outside of this book- and database-oriented environment, scholars have identified ways in which individuals who are not necessarily functioning as information seekers use symbols - or signsto similarly orient themselves to the phenomena in the world around them: phenomena that may not be information. This opening up of information - and especially documents - to a wider range of forms began with Suzanne Briet in 1951. Michael Buckland's seminal articles on the nature of information (1991) and documents (1997) brought Briet's ideas to a wider audience. This distinctive path is clearly articulated in Ron Day's 2014 book, Indexing It All, wherein he 
"examines the transition of indexes from being explicit professional structures that mediate the relation of user needs and documentary information in seeking, searching, and retrieving to being implicit infrastructural devices in everyday information and communication acts" (2). The dimensions of indexing thus have broadened considerably.

With a broader perspective comes the possibility for questions set in new contexts. One such set of questions that has emerged involves the relationship between indexing and memory in communities. Bowker (2005), for example, describes how scientific communities indexed their pasts with information technologies in order to remember them. Similarly, Zerubavel (2003) writes that "the social nature of human memory is evident not only in the actual content of our recollections but also in the way they are mentally packaged" (4).

Collective memory is, according to philosopher Paul Ricoeur (1992, 2004), narrative in nature. He describes the relationship between narratives and real life in this way: Narratives are not real life, which does not follow neat narrative structures. However, narratives represent real life, and their basic structure - beginning, middle, and end - is able to approximate the temporal arc within which all human action occurs. Ricoeur thus helps to define the kind of structure an index may have when it is not officially organized or uniformly distributed.

The field of collective memory recognizes that we index memories. However, it prioritizes places' role in that indexing. For instance, Hutton (1993) writes that the political significance of commemoration derives from "strengthen[ing] places of memory, enabling fading habits of mind to be reaffirmed and specific images to be retrieved more easily" (80). Likewise, documents are physical elements in our world that may perform roles similar to places of memory. Unlike these places, however, documents may accompany us throughout all the spaces of our lives. This perhaps positions them to more powerfully strengthen those habits of mind.

The fields of $\mathrm{KO}$ and collective memory acknowledge that communities structure their collective memory. However, we are left with some questions: Do documents, like places, play a structuring and organizing role? What does that role look like? How does this structuring and organizing contribute to a collective identity?

\section{Methodology}

I explore the indexing of collective memory first through archival research, which provides historical context for my case study documents. Specifically, it establishes a timeline for the unfolding of the UCC's collective memory as it is tied to the documents. It also offers insight into intentions related to the creation and distribution of the documents and into reactions to these documents. I conducted archival research at the United Church of Canada Archives in Toronto and the collections of Huron University College and St. Peter's Seminary in London, Ontario. I looked at the records of the church's Moderators and of the General Council meetings, committee reports, and correspondence from members of congregations concerning the church's Apology. I also studied the three main periodicals related to the UCC-Observer, Gathering, and Mandate - to get a sense of the public communication surrounding the documents. I perform thematic readings of the archival material based on Riessman's (2008) narrative method of analysis. The purpose of my archival analysis is to identify narratives concerning reconciliation found in the UCC community. I then compare the structure of these narratives to the traditional 
library-focused index structure as well as the structure of indexes as described by scholars in the tradition of Briet.

\section{Findings}

My research indicates that the UCC's documents contribute to collective memory through a fourstage process.

1. The phenomenon of the event or idea is captured in the form of a document. This is the moment of "indexing" in the larger world context: The document now represents, or stands in for, the original phenomenon.

2. The document goes through a document lifecycle — similar to Schellenberg's records lifecycle (1956) — as it is referenced, compiled, reformatted, copied, distributed, or preserved. Throughout this cycle, the indexed phenomenon is passed through space and time as it moves within this continuum, changing slightly with each new iteration.

3. Individuals have opportunities to encounter each iteration.

4. Those encounters are processed by individuals according to their own identities.

We see these four steps with the movement of the Apology into a group of documents. First, the Apology is captured as a document; in its very first official moment, it was read from a piece of paper. Next, the Apology is echoed in the form of a memorial cairn, plaques, paper and digital documents, and numerous references in other documents. Subsequently, each new iteration allows encounters with the Apology far from its temporal-spatial origin in 1986 Sudbury, Ontario. Each new encounter reinforces the centrality of the Apology to the UCC's story. Finally, people either adjust their own narratives to more closely match the church's or to differentiate themselves from it. This is a complex step that depends on our telling of our own stories.

\section{Discussion}

The findings highlight four characteristics of documents and collective memory. First, the process anchors the originating phenomenon in the world. As a physical manifestation of representations of the phenomenon, documents create the possibility for encountering it and guarantee that it can be referenced. Second, the interplay between a phenomenon and a group of documents contributes to collective memory. A group of documents positioned around a single phenomenon repeats the reference multiple times, filling in the stages of its narrative arc. Third, collective memory often involves an interplay between event and document. The Apology moved from event into document and back into event numerous times. Each movement was tied to a new document lifecycle, each cycle reinforcing the church's narrative. Finally, collective memory has a flexible nature, involving both stability and evolution. This is closely related to its narrative structure, which ensures that the overall story remains the same, even as elements of the story, such as sequence or character, are framed in a new light. The documents ensure continuity by constantly orienting the community towards a common phenomenon.

Simultaneously, the documents ensure that a variety of perspectives, details, and interpretations of the Apology continue to come to light.

\section{Conclusion}


The archives provide compelling evidence that the UCC's documents structure and organize the community's collective memory. They also offer multiple points of view on what that structuring looks like. When interpreted through the frames of $\mathrm{KO}$ and collective memory, these perspectives describe documents as integral to the development and maintenance of the UCC's evolving collective memory.

My study supports Furner's (2009) identification of identity, aboutness, relevance, and diachrony as the core concerns of $\mathrm{KO}$, even when the questions are moved into new contexts. What changes from the traditional KO context is the move of the documents from the object acted upon by indexes to the mechanism of indexing. The consistency also looks different in this context. There is no single indexer who judges the aboutness of the church's identity. Neither is there a single "information user" who judges relevance. I argue that, in fact, the role documents play in collective memory collapses the indexer's aboutness and the searcher's relevance into the community itself and the consistency derives from the stability of the church's narrative.

As part of the larger world context approach that has recently coalesced within KO, my study reinforces the idea that indexes are part of the infrastructural devices of our everyday lives. It simultaneously complicates that idea, suggesting that indexes are not always as determinative for our lives as some scholars suggest. In the UCC, the indexed collective memory is not enforced but repeatedly suggested, giving individuals some freedom to position their own identities within the community's. This realization opens further opportunities for inquiry into the nature of indexes that work in other kinds of social environments.

\section{Reference List:}

Bowker, G. C. (2005). Memory Practices in the Sciences. Cambridge, MA: The MIT Press.

Briet, S. (2006). What Is Documentation? English Translation of the Classic French Text. (R. E. Day, L. Martinent, \& H. G. B. Anghelescu, Trans. \& Eds.). Lanham, MD: The Scarecrow Press. (Original work published 1951)

Buckland, M. (1991). Information as Thing. Journal of the American Society for Information Science 42(5), 351-360. Doi: 10.1002/(SICI)1097-4571(199106)42:5<351::AIDASI5>3.0.CO;2-3

Buckland, M. (1997). What is a "Document"? Journal of the American Society for Information Science 48(9), 804-809. Doi: 10.1002/(SICI)1097-4571(199709)48:9<804::AIDASI5>3.0.CO;2-V

Day, R. (2014). Indexing It All. Cambridge, MA: The MIT Press.

Furner, J. (2009). "Identity": A Philosophical Approach to an Enduring Issue in Knowledge Organization. Knowledge Organization 36(1), 3-16.

Hutton, P. H. (1993). History as an Art of Memory. Hanover, NH: University Press of New England. 
Ricoeur, P. (1992). Oneself as Another. (K. Blamey, Trans.). Chicago: The University of Chicago Press. (Original work published 1990)

Ricoeur, P. (2004). Memory, History, Forgetting. (K. Blamey \& D. Pellauer, Trans.). Chicago: The University of Chicago Press. (Original work published 2000)

Riessman, C. K. (2008). Narrative Methods for the Human Sciences. Los Angeles: Sage Publications.

Schellenberg, T. R. (1956). Modern Archives: Principles and Techniques. Melbourne, Victoria, Australia: FW Cheshire.

United Church of Canada. (1986). 1986 Apology to Indigenous Peoples. Retrieved from https://www.united-church.ca/sites/default/files/resources/apologies-response-crest.pdf

Veracini, L. (2017). Introduction: Settler Colonialism as a Distinct Mode of Domination. In E. Cavanagh \& L. Veracini (Eds.), The Routledge Handbook of the History of Settler Colonialism. London: Routledge. (pp. 1-8).

Weinberg, B. H. (2017). Indexing: History and Theory. In J. D. McDonald \& M. Levine-Clark (Eds.) Encyclopedia of Library and Information Science ( $4^{\text {th }}$ ed.). Boca Raton: Taylor \& Francis. (pp. 1978-1991). DOI: 10.1081/E-ELIS4-140000154

Zerubavel, E. (2003). Time Maps: Collective Memory and the Social Shape of the Past. Chicago: The University of Chicago Press. 